\title{
Epidemiology and Outcome of Severe Hepatitis A Infection in Children in Kuwait
}

\author{
Entesar Husain $^{\text {a }}$ Jaffar A. Al-Tawfiq ${ }^{c}$ Khalid Husain ${ }^{b}$ \\ ${ }^{a}$ Department of Pediatrics, Infectious Diseases Hospital, and ${ }^{b}$ Department of Pediatrics, Al-Amiri Hospital, \\ Kuwait; ${ }^{C}$ Internal Medicine Services Division, Dhahran Health Center, Dhahran, Saudi Arabia
}

\section{Key Words}

Hepatitis A virus $\cdot$ Hepatitis A vaccine $\cdot$ Kuwait

\begin{abstract}
Objective: To describe the epidemiology, clinical features and outcome of hepatitis A virus (HAV) infection in children in Kuwait. Subjects and Method: The medical records of 350 patients (age 0-16 years) admitted to the Infectious Diseases Hospital, Kuwait, between January 2000 and December 2002, with hepatitis A infection were reviewed. Results: The mean age was $8.6 \pm 3.8$ years and $47 \%$ of patients were between 7 and 12 years old. Kuwaiti children comprised $44 \%$ of admitted patients. The largest proportion of children with hepatitis A (34\%) were from the northern part of the country. HAV infection was prevalent throughout the year with a peak during the months of August to October. Of the Kuwaiti children, $31 \%$ reported a history of contact with jaundiced patients, while $52 \%$ of the non-Kuwaiti children had a history of recent travel prior to their illness. Patients had symptoms for a mean of $6 \pm 3.6$ days prior to presentation. The mean length of hospitalization was $5.8 \pm 2.9$
\end{abstract}

This paper was presented in part at the 41st Annual Meeting of the Infectious Diseases Society of America (IDSA), San Diego, Calif., USA, October 9-12, 2003 (abstract No. 582).

\section{KARGER}

Fax +4161306 1234 E-Mail karger@karger.ch www.karger.com
(C) 2006 S. Karger AG, Basel

$1011-7571 / 06 / 0154-0266 \$ 23.50 / 0$

Accessible online at:

www.karger.com/mpp days. The rate of complications of HAV infection was $6 \%$ and only one child required admission to the intensive care unit for fulminant hepatitis. None of the patients had permanent sequelae. Conclusions: HAV infection is a significant cause of morbidity for children in Kuwait. The disease is mostly prevalent in preschool and school age children. Despite the excellent outcome of all patients, a considerable number of patients tend to have a complicated course and prolonged hospitalization. In view of these data, hepatitis $A$ vaccine should be considered as a part of routine childhood immunization in Kuwait.

Copyright (C) 2006 S. Karger AG, Basel

\section{Introduction}

Hepatitis A virus (HAV) is the most common cause of viral hepatitis [1]. The virus is transmitted from person to person through fecal-oral route. Hepatitis A is primarily an infection of childhood and is mostly asymptomatic [2]. When symptoms are present, they consist of nonspecific gastrointestinal manifestations like nausea, vomiting and abdominal pain. These symptoms may be followed by an acute onset of jaundice and discolored urine for which patients usually seek medical attention. The outcome of HAV infection is excellent with only $0.35 \%$ of patients developing fulminant hepatitis during the course of infection [3]. 


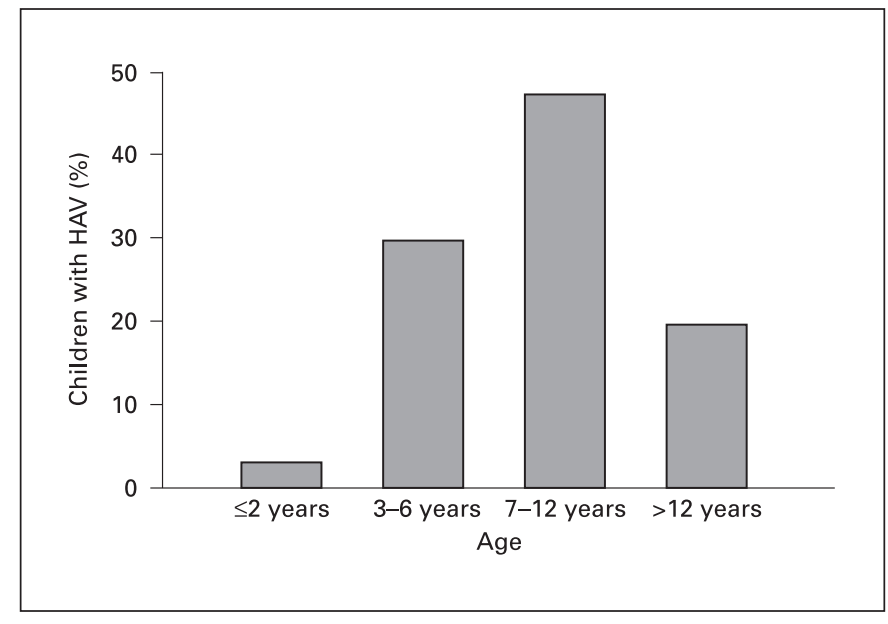

Fig. 1. Age distribution of children with $\mathrm{HAV}$ infection in $\mathrm{Ku}-$ wait.

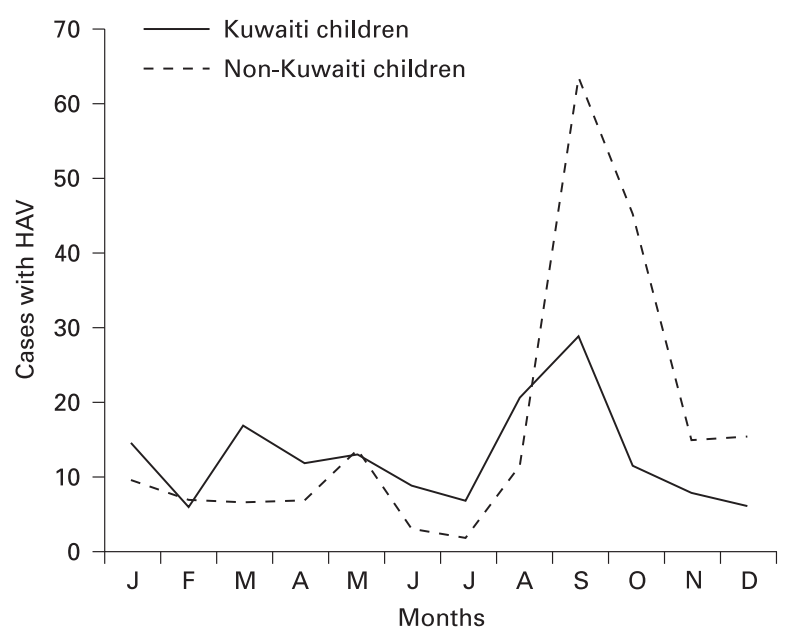

Fig. 2. Seasonal distribution of HAV infection: Kuwaiti and nonKuwaiti children.

Hepatitis A is an endemic infection in developing regions like Southeast Asia, South America, Middle East and Africa [4]. Available data from the Middle East indicate a high level of HAV seroprevalence among adults reaching up to $60 \%$ in some countries [5]. Recently, changes in the epidemiologic features of HAV infection have been noticed in areas with improved living standards with a shift in the age of infection towards older children and young adults [5].
Kuwait is a country where HAV infection is common [6] and HAV vaccine is not routinely administered to children. The aim of this study was to define the recent epidemiologic features and outcome of severe hepatitis A infection requiring hospitalization.

\section{Subjects and Methods}

Kuwait is a Middle Eastern country with an area of $17,820 \mathrm{~m}^{2}$. In the year 2002, Kuwait had a population of $2,363,325$ out of which $732,630(31 \%)$ were under the age of 18 years. Expatriates represented $63 \%$ of the total population with a majority from Arab countries like Egypt, Syria and Lebanon, and from South East Asia. Most parts of the country have been urbanized with a significant advancement in the socioeconomic status in the last two decades. The Ministry of Health is the major provider of the health care system through six regional health care districts. The Infectious Diseases Hospital is a major hospital and has been the only referral center for all suspected cases of infectious hepatitis since the early 1960s. All patients with any form of hepatitis are referred from all health care districts for further evaluation and investigations. Patients with severe infection are admitted if presenting with severe abdominal pain, persistent vomiting, dehydration, encephalopathy or laboratory evidence of hepatic failure such as hypoglycemia or distorted coagulation profile.

This study is a retrospective review of medical records of patients admitted with acute HAV infections from January 1st, 2000 to December 31st, 2002. Acute HAV infection was defined as the presence of specific HAV IgM in the sera of patients during the study period. Pediatric patients between 0 and 16 years of age were included in the study. During the study period, 1,160 children with positive HAV IgM were referred to the Infectious Diseases Hospital. This number represents an annual incidence rate of 53 per 100,000 population in the previously specified age group. Only 350 patients were admitted because of severe hepatitis. The data collected from this group of patients were subjected to further analyses. The patients' demographics, season of the year, mode of acquisition of the infection, clinical presentation, and outcome were collected. Statistical Package for Social Sciences (SPSS for Windows version 10.0) was used to analyze the data.

\section{Results}

Kuwaiti children comprised $44 \%$ of the 350 patients, and the remaining were Arabs (49\%) and Asians (7\%). The mean age was $8.6 \pm 3.8$ years with an equal male to female ratio. Most (47\%) of the patients were between 7 and 12 years of age and 30\% were between 3 and 6 years old (fig. 1). Patients living in the northern part of the country constituted the majority of the patients (34\%). A seasonal peak of reported cases (27\%) was noted in September and the least in July (2\%) (fig. 2). 
In examining the mode of acquisition, a history of contact with jaundiced patients was present in 39\% of Kuwaiti children, while a travel history was present in 50\% of non-Kuwaiti (fig. 3).

Initial symptoms of hepatitis were present for a mean of $6 \pm 3.6$ days prior to diagnosis and hospitalization. The most common reported symptoms at the time of presentation were darkening of the urine $(67 \%)$, yellowish discoloration of the eyes (61\%), and abdominal pain $(27 \%)$. An underlying health condition was present in 7.4\% and included glucose-6-phosphate dehydrogenase deficiency $(\mathrm{n}=10)$, insulin-dependent diabetes mellitus $(n=4)$, epilepsy $(n=4)$, bronchial asthma $(n=3)$, Down's syndrome $(n=1)$, congenital heart disease $(n=1)$, juvenile rheumatoid arthritis $(\mathrm{n}=1)$, and Bartter syndrome $(\mathrm{n}=1)$. However, none of the patients had a chronic liver disease.

The mean length of hospitalization was $5.8 \pm 2.9$ days and the mean duration of normalization of liver transaminases was $21.7 \pm 7.2$ days in 245 patients who attended follow-up visits. Complete resolution of HAV infection had occurred in $94 \%$ of patients without complications and only $6 \%$ of the patients had documented complications. All complications were observed in children more than 7 years of age. These complications included prolonged jaundice (lasting $>1$ month) in 7 patients and co-infection with other viruses in 7 patients (Epstein-Barr virus in 3 patients, hepatitis E virus in 3 patients, and cytomegalovirus in 1 patient). Fulminant hepatitis was noted in 1 patient who required admission to the intensive care unit. However, there were no fatalities among the study population.

\section{Discussion}

HAV is prevalent in the Arabian Gulf countries. Seroprevalence data from Qatar and United Arab Emirates have shown that by the age of 20 years $60 \%$ of the population are HAV positive [5]. More recent data from Saudi Arabia showed that $79 \%$ of children less than 18 years of age were positive for hepatitis A [7]. Compared to a previous study in Kuwait in 1981-1982 [8], there appears to be a decline in the observed incidence of HAV infection from $122 / 100,000$ to the estimated rate of 53/100,000 of the present study in children less than 18 years of age. This perceived decline in the incidence of HAV could be attributed to multiple factors including improved water supplies, enhanced sewage disposal, reduced crowding and the overall awareness of hygiene.

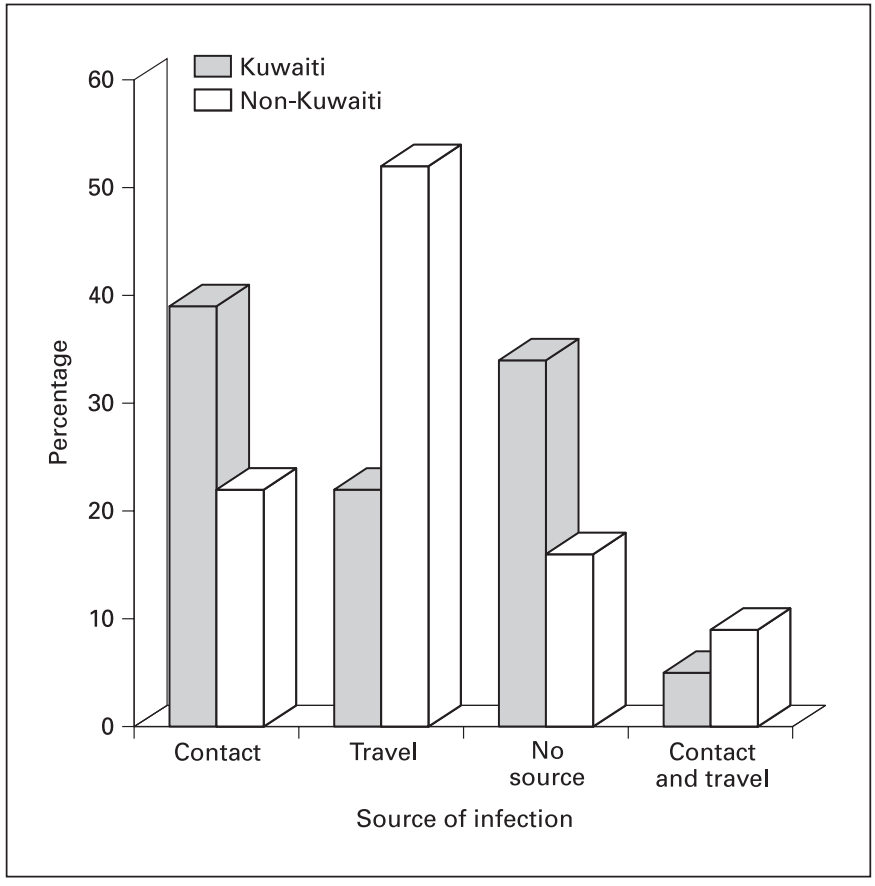

Fig. 3. Source of HAV infection in children in Kuwait: difference between Kuwaiti and non-Kuwaiti children.

The above-mentioned previous study conducted in 1981-1982 has reported that the majority of HAV infections occurred in the age group of $0-4$ years with a mean age of 5.6 years [8]. The current study, however, showed that the majority of affected patients were those between 7 and 12 years of age with a mean age of 8.6 years. A similar shift in the age of patients infected with HAV has been reported from Saudi Arabia [5] and Korea [9]. The decline in the incidence of HAV infection among individuals older than 12 years of age points toward the development of immunity secondary to natural infection with HAV during early years of life [5].

The rate of hepatitis A transmission among household contacts in Kuwait (39\%) is higher than that reported in the literature $(20-26 \%)[10,11]$. This finding may be explained by the fact that Kuwaiti families tend to live in an extended family pattern within the same household. This explanation is true particularly for the northern part of the country where $34 \%$ of the cases had originated. It has been shown that household contacts represent a great risk of acquiring HAV infection [10, 11] as explained in a model by Meyerhoff and Jacobs [12], where every 100 index cases aged 6-11 years would result in 47 secondary infections in the households and 
23 individuals would have overt infections. The peak incidence of HAV infection in September and October could be due to importation of the infection by returnees from endemic areas (other Arab countries) to the country at the end of summer vacation. Apparently, these individuals act as a significant source of HAV infection in Kuwait similar to what was described by Weinberg et al. [13] with importation of HAV infection across the US-Mexican border.

Despite the decline in the incidence of HAV infection in Kuwait, there has been a shift in cases towards older children who are at increased risk of morbidity and complications. Even though urbanization and infection control measures have a large impact on reducing the spread of HAV infection, immunization remains the most effective tool for preventing HAV infection. Two doses of hepatitis A vaccine given 6-12 months apart is safe, highly immunogenic [14] and provides a long-term protection [15]. Whether routine childhood HAV immunization in Kuwait would be cost-effective or not requires further studies. However, HAV vaccine has been suggested by some authors for areas where an upward shift in the average age of infection has occurred [9].
There are two shortcomings of this study: (a) examining only hospitalized children; consequently, the estimated incidence of HAV may not reflect the true HAV infection in the country; the true incidence of HAV infection is probably higher than stated since only $10 \%$ of patients were symptomatic and sought medical advice; (b) although this study estimated incidence and described epidemiology of HAV infection in children in Kuwait, information about the prevalence of the disease is lacking.

\section{Conclusion}

Our study provides insights into the recent epidemiologic features of HAV infection in a Middle Eastern country where widespread vaccination may have a significant impact on the burden of the disease. Further communitybased surveillance studies are needed to define the endemicity of the disease in Kuwait in order to support public health decisions regarding appropriate interventions including vaccination.

\section{References}

-1 Alter MJ, Gallagher M, Morris TT, Moyer LA, Meeks EL, Krawczynski K, Kim JP, Margolis HS: Acute non-A-E hepatitis in the United States and the role of hepatitis G virus infection. Sentinel Counties Viral Hepatitis Study Team. N Engl J Med 1997;336:741-746.

-2 Craig AS, Schaffner W: Prevention of hepatitis A with the hepatitis A vaccine. N Engl J Med 2004;350:476-481.

-3 Kemmer NM, Miskovsky EP: Infections of the liver; hepatitis A. Infect Dis Clin North Am 2000;14:605-615.

-4 Ciccozzi M, Tosti ME, Gallo G, Ragni P, Zotti C, Lopalco P, Ara G, Sangalli M, Balocchini E, Szklo AS, Mele A, SEIEVA collaborating group: Risk of hepatitis A infection following travel. J Viral Hepat 2002;9:460-465.

-5 Tufenkeji H: Hepatitis A shifting epidemiology in the Middle East and Africa. Vaccine 2000;18:S65-S67.

6 Ministry of Health, Kuwait. Vital Statistics Book, 2002.

\footnotetext{
Fathalla SE, Al-Jama AA, Al-Sheikh IH, Islam SI: Seroprevalence of hepatitis A virus in Eastern Saudi Arabia. Saudi Med J 2000;21:945948.

8 Nordenfelt E, Atack W, Al-Kandari, Al-Nakib W: Hepatitis A in Kuwait. J Kuwait Med Assoc 1985;19:103-108.

-9 Kang JH, Lee KY, Kim CH, Sim D: Changing hepatitis A epidemiology and the need for vaccination in Korea. Asian Pac J Allergy Immunol 2004;22:237-242.

10 Staes CJ, Schlenker TL, Risk I, Cannon KG, Harris H, Pavia AT, Shapiro CN, Bell BP: Sources of infection among persons with acute hepatitis A and no identified risk factors during a sustained community-wide outbreak. Pediatrics 2000;106:E54.

11 Bell BP, Shapiro CN, Alter MJ, Moyer LA, Judson FN, Mottram K, Fleenor M, Ryder PL, Margolis HS: The diverse patterns of hepatitis A epidemiology in the United States: implications for vaccination strategies. J Infect Dis 1998;178:1579-1584.

12 Meyerhoff AS, Jacobs RJ: Transmission of hepatitis A through household contact. J Viral Hepat 2001;8:454-458.

13 Weinberg M, Waterman S, Lucas CA, Falcon VC, Morales PK, Lopez LA, Peter C, Gutierrez AE, Gonzalez ER, Flisser A, Bryan R, Valle EN, Rodriguez A, Hernandez GA, Rosales C, Ortiz JA, Landen M, Vilchis H, Rawlings J, Leal FL, Ortega L, Flagg E, Conyer RT, Cetron M: The US-Mexico Border Infectious Disease Surveillance project: establishing bi-national border surveillance. Emerg Infect Dis 2003;9: 97-102.

14 Prevention of hepatitis A through active or passive immunization: recommendations of the Advisory Committee on Immunization Practices (ACIP). MMWR Recomm Rep 1999; 48:1-37.

15 Wiedermann G, Kundi M, Ambrosch F: Estimated persistence of anti-HAV antibodies after single dose and booster hepatitis A vaccination (0-6 schedule). Acta Trop 1998;69: $121-125$.
} 